Journal of Advances in Sports and Physical Education

Abbreviated Key Title: J Adv Sport Phys Edu ISSN 2616-8642 (Print) |ISSN 2617-3905 (Online) Scholars Middle East Publishers, Dubai, United Arab Emirates Journal homepage: https://scholarsmepub.com/jaspe/

Original Research Article

\title{
Coach Leadership in Football
}

\author{
Aida Shehu, Avdyl Kuriu, Edison Ikonomi ${ }^{*}$ \\ Department of Sport, Faculty of Movement Sciences, Sports University Tirana, Albania
}

DOI: $10.36348 /$ jaspe.2019.v02i10.001

| Received: 05.12.2019 | Accepted: 14.12.2019 | Published: 20.12.2019

*Corresponding author: Edison Ikonomi

Abstract

The coach of a football team with his leadership influences the performance of the team. Characteristic coach behaviors such as training and instruction, autocratic and democratic behavior, social support, positive feedback, influence the success of the team. The purpose of the study is to footballers investigate perceptions of the leadership style of football coaches under 15 and under 17, as well as coaches views of on their style of work, identifying differences. The subjects of the study are 104 football players. Study indicators indicate a high rating of footballers for behavior, coach training and instruction. Study indicators indicate a high rating of athletes for coach behavior, training and instruction. Democratic behavior is perceived as lower than instruction, while autocratic behavior is low, frequencies rarely dominate. Footballers feel social support, encouragement and positive feedback is high.

Keywords: Leadership, democratic, autocratic behavior, social support, positive feedback.

Copyright @ 2019: This is an open-access article distributed under the terms of the Creative Commons Attribution license which permits unrestricted use, distribution, and reproduction in any medium for non-commercial use (NonCommercial, or CC-BY-NC) provided the original author and source are credited.

\section{INTRODUCTION}

An individual, to be able to perform the job of a coach effectively, although he may have been a footballer for several years, will need other skills that are not the same as those he needed when he was a sportsman. In sport, each coach performs the leadership of footballers, organizes the sport life of the group. The coach performs a variety of complex tasks in his job, and to be effective, he must be prepared to perform the role of team leader, display great leadership capacity. The concept of leadership also exists in the sports context. The coach of a football team is a must have leader and his leadership impacts the performance and success of the team [1].

Leadership is the process of leading, directing individuals or groups to achieve goals. Outstanding leaders, as in any other field, also emerge in sports training environments, in the world of sport and there are many coaches who have demonstrated a great leadership capacity. Leadership is considered as the process of behavior, of the influence of individuals and groups towards the achievement of the set objectives [2].

An individual who is a coach has the authority to lead, but that does not make him a leader. It is imperative that team members recognize, acknowledge and legitimize his ability, authority. The coach needs to win the respect of the team, the respect that is earned by demonstrating superior knowledge and skills, earning credibility through work of a clear commitment to the team, featuring charisma. To be a good leader, the coach must have the ability to have the vision, to give the footballers, the team the vision, and to know how to turn that vision into reality. In order to realize the vision the coach must develop and maintain an effective team culture, which is about how things are done and functioning in the team, creating a climate for success, creating a winning mindset, cultivating dedicating, pride, building the team spirit. What makes effective leader. The leader is "born" or "becomes" such. Are questions that for a long time psychologists have tried to give answers. Numerous researches have yielded a number of ideas in response to these questions, which reflect on several lines, such as the leaders personal characteristics, the way they behave in leadership style, the situations in which leaders operate and of member characteristics [3].

Since the early 20th century it was thought that leadership was an innate quality, people were born to be leaders or not. This idea had to do with the theory "big man" of leadership. According to this theory it believed that leaders possess some characteristic and if someone does not have them, cannot be a leader. Those individuals who are born with these particular characteristics are likely to rise to the leadership 
positions, and this means that the leader is born. In this regard an individual who is a leader in one area of life (e.g., in commerce), will also be a good leader in another area (e.g., in sports). This theory did not last long because it was understood that excellent leaders in some tasks were not good leaders in some other tasks. Sharp observers noted that leaders do not act all the same. They had different styles of behavior. There was an enthusiasm for this development and research began to explore the styles of behavior that best suited tasks of different kinds. Recognizing that a style was more effective for some types of tasks, rather than to some other types, researchers began to look at the factors of the situation. This concept was developed that was really the situation that allowed ordinary people the opportunity to become leaders. This was called the "big bang" theory, which held that something spectacular must happen to transform a certain person into a leader [4].

- Also, while studying how leadership styles interacted with the task, it was observed that members had changes in personality and needs, so they responded to the leader and influenced the leader's effectiveness. One hypothesis that relies on sport is that a good leader must be the right person at the right time and in the right place. Some qualitative elements of an effective leader according to Martens, 1987 are [5]:

- Leaders provide direction; they set goals with a vision for the future.

- Leaders build a psychological and social environment conducive to achieving team goals.

- Leaders install values; motivate members to follow the team's objectives.

- Leaders face problems that arise and resolve conflicts.

- Leaders communicate, which is a critical and necessary skills in their engagement.

Chelladurai [6] making a synthesis of most of the leadership models proposed earlier, formulated his theory leadership specified for the sporting environment, highlighted the complexity of the leadership process in the sports environment.

Chelladurai [7] proposed a multi-dimensional model, conceptualizing the leadership model as an interactive process. Optimal team sports performance and level of satisfaction are a function of the competition between three types of leader behavior that are: the behavior required, the situation required, the behavior preferred by members and real behavior of action as a leader. The optimal performance and satisfaction of team members happen if all three aspects of leader behavior are matched. So if the leader behaves according to the particular situations and this behavior is in line with the favorite behavior of the members, the athletes will achieve the best performance and feel satisfied. Behaviors deriving from the characteristics of a sports situation, in which the leader is found, are the behaviors to be performed, that is, required of that situation. The situation requires a leader to behave in defined ways. In other words, situations such as the organizational level of the team (professional or diligent), team or individual sport, interactive or interactive sport, time available, are what dictate the leader's behavior.

Preferred behaviors are leader behaviors preferred by group members, largely dependent on the characteristics of the athletes. Athletes also have preferences for leader specific behaviors. Membership characteristics, such as need for achievement, social connection, competence in task or even age, gender, sport experience influence their preferences for training, social support, coach feedback. It may happen that the group members learn some behaviors, grow up with them and are thus educated to prefer them [8].

The leader's real behavior is his behavior. It depends on the characteristics of the leader, such as personality, ability, experience, but is also influenced by other things, what the situation dictates, or the characteristics of the members. Real behavior is believed to be indirectly influenced by group preferences and what situations dictate. Both the characteristics of the situation and the members of the group will influence the behavior of the coaches. Absolutely the best performance and team satisfaction will be helped by competitiveness from three aspects of the coach's behavior. So the coach's behavior must be coherent with the situational requests and behaviors preferred by the athletes. Coaches in their work are characterized by assigned leadership style. The style of leadership coach has to do with the typical way leads, it helps the team, athletes perform tasks, to achieve assigned objectives and be satisfied their needs. Many coaches use different leadership styles, dealing with the typical way they lead, help the team, athletes perform tasks, achieve objectives. There is a tendency on the part of a coach to direct in a particular way [5].

In searches for style of leadership Martens 1987, [5] identifies three different styles of leadership, autocratic, democratic and permissive. Two styles, democratic and autocratic, are significant. Leadership styles have their own characteristics.

Democratic style of leadership encourages the involvement of the group members, ideas heard, individuals are encouraged to participate in decisions related to the preparation of the performance of group tasks. A coach with democratic style allows athletes to participate in decisions about objectives, methods of training, tactics and strategies of the game [9].

The democratic style coach encourages the participation and consensus of the athletes, taking into consideration each opinion, gives space to the individual initiative for the objectives, the training 
program. It is said in a synthetic way that the democratic style is focused on the cooperative athlete and the relationship oriented. If a team is led in this style, when the leader is absent, the team continues to work and when things go wrong, there is cooperation between the members [10].

Autocratic style requires no ideas, no thoughts. It tells the group what to do and is appropriate especially when a task must necessarily be performed. A coach with autocratic style makes decision making independent and emphasizes personal authority regarding decisions. Generally not required input from athletes. The coach's autocratic style is usually victory oriented, commanding and task oriented [9].

Coach with autocratic style sets the general and specific directives of the athletes regardless preferences of their opinions, give orders excluding individual initiative and reserving themselves every decision. If a team headed with this style, when the leader is absent, then the team members, reduce the level of employment, become aggressive toward each other, especially if things go wrong [10].

The permissive style, really not a leadership style, is meant to leave the team, the members to deal with things in their own way. Although leaders can help members to face difficulties, they do not provide direction and so is unlikely to achieve the objectives. Team members who addressed this style tend to be aggressive toward each other when things go wrong and removed easily from difficulties [9].

There is no only a way to guide sportsmen, in all situations. A coach does not have to act completely one style or the other. Each style is more effective in certain circumstances and in some other circumstances not. The ideal coach is one who is flexible and adaptable to his leadership style. This style is neither democratic nor autocratic, but a mixture of the two best, the most appropriate for situation. In essence, training should not be only democratic or autocratic [11].

Leader behaviors are more optimal when they are adapted to a variety of situations. So, the challenge of a coach is to determine which style is best for the situations and be flexible enough to adapt his dominant style to the particular situation. The most appropriate style depends on the situation factors and the characteristics of the members.

Leader characteristics, leadership style, situational factors and characteristics of followers, followers, and ways of their interaction determine the effectiveness of a leader. Realization of an interactive process between leader and athletes characteristics, leadership style is important to have an effective leadership. Specific characteristics of athletes, such as gender, experience, maturity, nationality, ability level and personality of athletes interact with leader characteristics and leadership style [12].

Chelladurai and Saleh in 1980, [13] developed a questionnaire called the Scale Leadership in Sport (SLS). When it comes to leader behavior, there are five dimensions of his behavior that include athlete's preferences for specific behaviors, athlete's perceptions of their coaches behaviors and coaches perceptions of their behaviors. Scale Leadership in Sport examines five key characteristic behavior of a coach as a team leader that is:

- Training and instruction are behaviors orientated coach to improve the performance of athletes, commitment to training, coaching for sports specific competencies, clarify the relationships between the members, structure and coordinate the activities of members. A coach makes great efforts to improve athlete performance by providing technical instruction on skills, techniques and strategies, emphasizing rigorous training, coordinating team member activity. The coach is a good leader if he daily provides athletes with adequate technical training, support and motivates athletes in order to realize his vision, so in a way he is an expert leading the athletes to reach their capacities and achieve the best results.

- Democratic behaviors are coach behaviors that enable a wide participation of athletes in decision making related to group objectives, training methods, tactics and competition strategies. Highly perceived coaches in coaching and guidance, with democratic behavior, social support and positive feedback, with low level autocratic behavior, have teams that are more cohesive.

- Autocratic behaviors are coach behaviors that have a high level of authority and are characterized by decisions that do not depend on the influence of athletes. An autocrat style coach makes decisions independently and emphasizes personal authority in the work of decision making. Generally, opinion from sportsmen is not required.

- Social support, are coaching behaviors that express concern for the wellbeing of athletes, the team atmosphere and positive interpersonal relationships of the team. The coach gives high social support, shows concern; try to stabilize warm relationships with them.

- Positive feedback, behaviors that reinforce athletes by appreciating positive performance. The coach that stands for positive feedback at a high level, consistently praise or rewards for good performance athletes. Positive feedback is about performance and limited to the sports context. 


\section{PURPOSE OF STUDY}

Is to investigate the perception of footballers to the leadership style of football coaches $U 15$ and $U$ 17, as well as coaches' perceptions of their work style in evidencing differences

\section{OBJECTIVES OF STUDY}

Identify: trainer behavior, training and instruction, autocratic behavior, democratic behavior, social support, positive feedback.

\section{METHODOLOGY}

The subjects of the study

The subjects of the study are footballers from Albania, Serbia and Northern Macedonia U 15, as well as Dinamo and Partizani U 17 teams from Tirana. There are 104 footballers in total. The data presented in Table 1.

Table-1: Study subjects

\begin{tabular}{|c|c|c|c|c|c|}
\hline Teams & Albania & Serbia & North Macedonia & Dinamo & Partizani \\
\hline U 15. & 20 & 10 & 15 & - & - \\
\hline U 17. & - & - & & 32 & 27 \\
\hline
\end{tabular}

\section{Instrument}

As instrument of study used questionnaires Scale Leadership in Sport (SLS) [13]. The questionnaire contains 40 questions related to the coach's behavior as a team leader. Answers are given on a Likert scale from 1 to 5 . (5 always, 4 often, 3 sometimes, 2 rarely, 1 never.) The questionnaire is divided into 5 subscales. There are 13 questions (1-13) on training and instruction, 9 questions (14-22) on democratic behavior, 5 questions (23-27) on autocratic behavior, 8 questions (28-35) on social support and 5 questions (36-40) for positive feedback. The questionnaire was completed individually by the footballers before a training process; the authors distributed the questionnaire and previously provided instructions for understanding and completing it correctly.
SPSS software version 22 was used for the processing of the data collected (Statistical Program of Social Sciences, SPSS).

\section{RESULTS}

Analysis of the coefficient $\alpha$ Cronbach shows that results vary at a confidence level mainly high, but acceptable for the two subscales of the questionnaire. Cronbach alpha for the forty questions of the five scale questionnaire, is $\alpha=.843$. While calculations on the questions for each scale of the questionnaire, the indicators are: 1. For behavioral questions related to training and instruction, $\alpha=.857 ; 2$. For democratic behavior questions, $\alpha=.815 ; 3$. For autocratic behavior questions, $\alpha=.800 ; 4$. For behavioral questions social support, $\alpha=.700 ; 5$. For positive feedback questions, $\alpha$ $=.700$;

Table-2: Average indicators of coach behavior, footballers U 17 teams Dinamo, Partizani and U 15 Albania, according to the five subscales of the questionnaire

\begin{tabular}{|c|c|c|}
\hline Coach behavior & Perception footballers & Coach self- perception \\
\hline training - instruction & 4.41 & 4.14 \\
\hline democratic behavior & 3.33 & 2.77 \\
\hline autocratic behavior & 2.58 & 2.39 \\
\hline social support & 3.38 & 3.26 \\
\hline positive feedback & 4.28 & 4.02 \\
\hline
\end{tabular}

Table-3: Average indicators footballers perceptions of $U \mathbf{1 5}$ for coach behavior according to the five subscales of the questionnaire

\begin{tabular}{|c|c|c|c|}
\hline Coach behavior & Albania & Serbia & North Macedonia \\
\hline training - instruction & 4.47 & 3.96 & 4.32 \\
\hline democratic behavior & 2.75 & 3.25 & 3.93 \\
\hline autocratic behavior & 2.22 & 2.38 & 3.83 \\
\hline social support & 3.20 & 3.09 & 3.67 \\
\hline positive feedback & 4.49 & 4.40 & 4.22 \\
\hline
\end{tabular}


Table-4: Averages by 40 questions of footballers perceptions

\begin{tabular}{|l|c|c|c|c|c|}
\hline & Mean & S/ Deviation & & Mean & S/ Deviation \\
\hline Question1 & 4.46 & .867 & Question21 & 3.62 & 1.393 \\
\hline Question2 & 4.62 & .644 & Question22 & 2.47 & 1.406 \\
\hline Question3 & 4.53 & .672 & Question23 & 3.04 & 1.418 \\
\hline Question4 & 4.63 & .715 & Question24 & 2.36 & 1.460 \\
\hline Question5 & 4.37 & .732 & Question25 & 2.68 & 1.482 \\
\hline Question6 & 4.46 & .725 & Question26 & 2.31 & 1.411 \\
\hline Question7 & 4.49 & .727 & Question27 & 2.53 & 1.542 \\
\hline Question8 & 4.36 & .730 & Question28 & 3.95 & 1.193 \\
\hline Question9 & 4.38 & .815 & Question29 & 4.27 & .962 \\
\hline Question10 & 4.31 & .736 & Question30 & 4.12 & .980 \\
\hline Question11 & 4.23 & .763 & Question31 & 2.35 & 1.476 \\
\hline Question12 & 4.38 & .734 & Question32 & 3.30 & 1.259 \\
\hline Question13 & 4.15 & .963 & Question33 & 4.36 & .913 \\
\hline Question14 & 3.46 & 1.275 & Question34 & 2.95 & 1.457 \\
\hline Question15 & 3.57 & 1.254 & Question35 & 1.81 & 1.276 \\
\hline Question16 & 3.80 & 1.042 & Question36 & 4.05 & 1.161 \\
\hline Question17 & 3.38 & 1.328 & Question37 & 4.42 & .835 \\
\hline Question18 & 2.95 & 1.524 & Question38 & 4.11 & 1.037 \\
\hline Question19 & 3.36 & 1.248 & Question39 & 4.40 & .876 \\
\hline Question20 & 3.38 & 1.280 & Question40 & 4.44 & .806 \\
\hline
\end{tabular}

\section{DISCUSSIONS AND CONCLUSIONS}

Concerning coach behavior (questions 1-13), training - instruction, indicators of footballers perception, speak of a high rating of footballers for coach performance. The average is 4.41 and varies from 4.15 to 4.63 (between, often and always). So footballer perception of the coach's performance in training instruction is high. In particular appreciated and has a maximum rating of coach work related to his explanations of techniques and tactics, and that he requires and will be provided if understood correctly by footballers. For the same behavior the coaches' own opinion of their performance is 4.14 , slightly less than the perception of their footballers. It is explained, that trainers for their activity, are of the opinion that the dominant behavioral frequency is often, for good training. While the footballers perceive more than often. On indicators for teams $\mathrm{U} 15$, the perception of Albanian footballers is higher at 4.47 versus 3.96 for Serbia and 4.32 for Northern Macedonia.

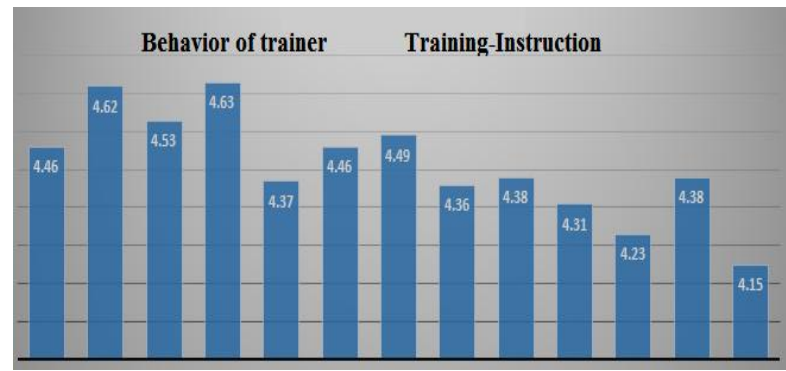

Fig-1: Concerning trainer behavior (questions 1-13), training instruction

Democratic behavior, (questions 14-22), average is 3.33 , ranging from 2.47 to highest 3.80 . So democratic behavior is perceived with lower indicators, indicators are between sometimes and often, but the answer is sometimes dominant. Thus, the opinion of judgments the footballers about the objectives of the training tactics is not high. For the same behavior, the coaches' own opinion of their behavior is 2.77. So less than the perception of their footballers. Thus, from the responses of the footballers, but also of the reflection of the coaches, it is evident that this behavior does not find a wider space for the coaches. In particular, it is low for behavior, setting objectives or tactics that can be used footballer during the game and are between rarely and sometimes. While on issues like getting the opinion of footballer in decision making, opinions on training are between rarely and sometimes. Indicators for U 15 teams, perception of Albanian footballers is lower at 2.75, versus 3.25 for Serbia and 3.93 for Northern Macedonia, thus the perception of Albanian footballers for democratic behavior is lower than that of Serbia and Northern Macedonia. The indicators speak for a significant difference between $U 15$ and $U 17$ footballers, where U 15 is perceived as democratic at lower levels, between rarely and sometimes. So there is an opinion among coaches that U 15 players are about an age that needs to be instructed than to take ideas from them.

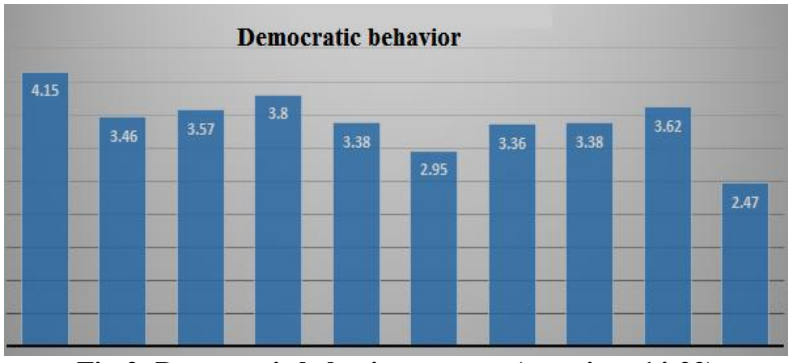

Fig-2: Democratic behavior answers (questions 14-22) 
Autocratic behavior, (questions 23-27), the average is 2.58 , ranging from 2.31 to 3.04 , so autocratic actions are between rarely until sometimes. While trainers themselves thought their behavior is 2:39, almost the same as their perceptions footballers. So while democratic behavior is somewhat low, it does not mean that autocratic behavior is high. Autocratic behavior is lower, frequency dominates rare for this behavior. Coach behaviors that do not explain their actions, that are not open to communication with footballers, or that does not allow footballers to question and discuss, are in a dominance of the frequency of behavior rarely. Indicators for U 15 teams, perception of Albanian footballers are lower 2.22, versus 2.38 for Serbia and 3.83 for Northern Macedonia.

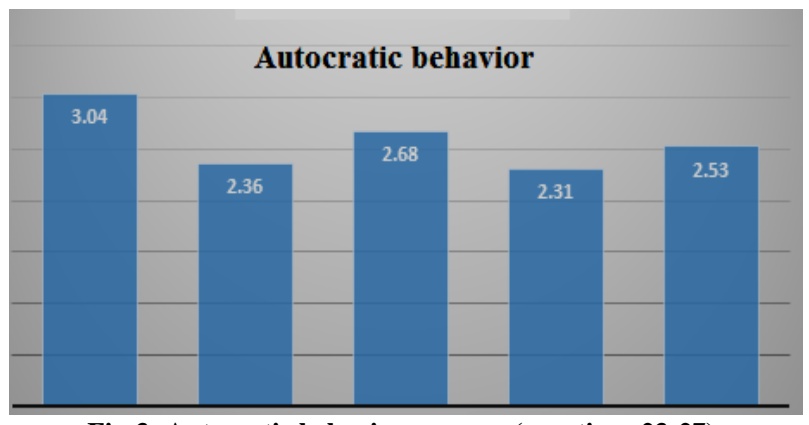

Fig-3: Autocratic behavior answers (questions 23-27)

Social support, (questions 28-35). Average 3.38, dominates the frequency towards often. Footballers feel the support of, in order to resolve conflicts between them, the encouragement to have confidence in themselves. While associated with the expression of affection to footballers is $3: 30$, so between sometimes and often, closer sometimes. There are signs of a connection unofficial close 2.95, so sometimes. For the same behavior the coaches' own opinion of their behavior is 3.26. So say the same perception of their footballers. Indicators for $U 15$ teams, perception of Albanian footballers are lower 3.20 versus 3.9 for Serbia and 3.67 for Northern Macedonia. So, the perception of Albanian footballers is lower than that of Serbian and Northern Macedonian footballers.

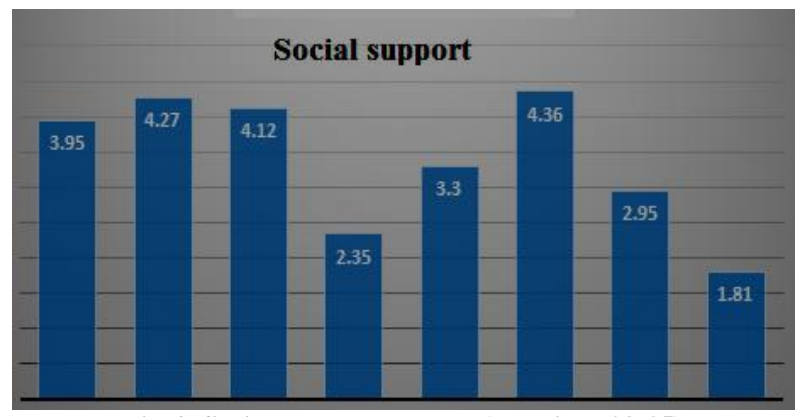

Fig-4: Social support answers (questions 28-35)

Positive feedback, (questions 36-40), mean 4.28 , footballers perceive that positive feedback is at a high level, in the space between often and always. The perception of coaches is 4.02, lower than that of footballers. Self-reflection evidences that coaches do not exaggerate always done, but often dominates. Indicators for the U15 teams, the perception of Albanian footballers are 4.49, versus Serbia's 4.40 and North Macedonia's 4.22. So almost the same. The indicators speak for a small difference of footballers $U$ 15 and $U$ 17. For $U 15$ they are higher than $U 17$, something different from other behaviors.

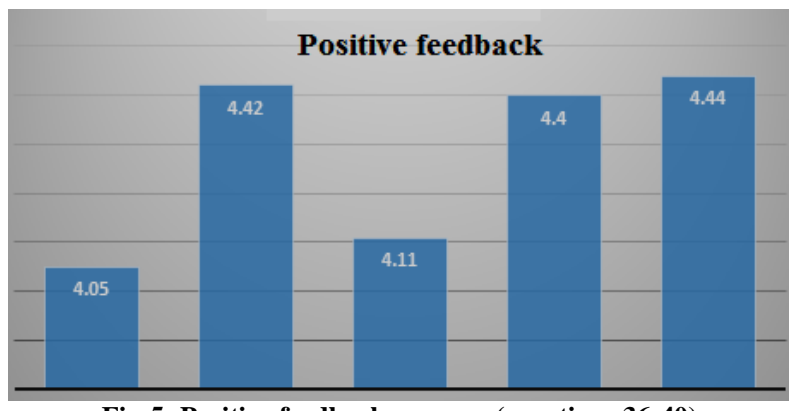

Fig-5: Positive feedback answers (questions 36-40)

The study helps to raise awareness of the coaches for their leadership, to sensitize them to find the right leadership in their activity, to increase the performance of the team and the footballers in particular.

\section{CONFLICT OF INTEREST}

Authors declare that they have no conflict of interest

\section{ACKNOWLEDGMENTS}

We wish to thank all: footballers and coaches, who helped and participated in our study.

\section{REFERENCES}

1. Horne, T., \& Carron, A. V. (1985). Compatibility in coach-athlete relationships. Journal of Sport Psychology, 7(1), 137-149.

2. Barrow, J. C. (1977). The variables of leadership: A review and conceptual framework. Academy of Management Review, 2, 233-251.

3. Çakioğlu, A. (2003). Leadership and satisfaction in soccer: examination of congruence and players' position. In partial fulfillment of the requirements for the degree master of science. 40-41, 48.

4. Weis, M. R., \& Friedrichs, W.D. (1986). The influence of leader beheviars coaches at tributes and instituzional variables on performance and satisffaction of collegate basketball teams. Journal of sport psychology, 8(5), 332-346.

5. Martens, R. (1987). Coaches guide to sport psychology. Human Kinetic. [BOOK]. ERIC Number: ED284858. 195.

6. Chelladurai, P. (1990). Leadership in sports. International Journal of sport psychology, 21(3), 328-354.

7. Chelladurai, P. (2007). Leadership in Sports. 
Handbook of sport psychology. Hoboken, New Jersey: John Wiley \& Sons, Inc, 113-135.

8. Garland, D. J., \& Barry, J. R. (1988). The effect of personality and perceived leader behavior on performance in collegiate football. The psychological record, 38, 237-247.

9. Weinberg, R., \& Gould, D. (2007). Foundations of sport and exercise psychology. Ed. Hum. Kinetics, 6(2), 194-200.

10. Antonelli, F., \& Salvini, A. (1989). Psicologia dello sport. Seconda edizione. Edilombardo, Roma, 262-
279, 306-308.

11. Cei, A. (1998). Psicologia dello sport. Il Mulino. Bologna, 259-269.

12. Chelladurai, P., \& Saleh, S. D. (1978). Preferred leadership in sports. Canadian Journal of Applied Sport Sciences, 3(5), 85-92.

13. Chelladurai, P., \& Saleh, S. D. (1980). Dimensions of leader behavior in sports: development of a leadership scale. Journal of Sport Psychology, 10(7), 34-45. 